\title{
Towards a Differentiated and Vocational Oriented Secondary Schoool Curriculum in Zimbabwe
}

\author{
1Bhebhe, S. \\ 'Dziva, M. \\ ${ }^{2}$ Maphosa, C. ${ }^{*}$ \\ 1 University of Venda, South Africa \\ 2 University of Fort Hare, South Africa
}

\section{Doi:10.5901/mjss.2014.v5n7p443}

\section{Abstract}

Curriculum should ideally be differentiated to suit the needs, capabilities and intelligences of the learners. However, learners are often exposed to an academic oriented curriculum even if this results in failure and production of unemployable school graduates. Underpinned by the multiple intelligences theory, in this paper the researchers explore an alternative to the current largely academic curriculum in the Zimbabwean education system. The concepts differentiated and vocational curricula are discussed and challenges of an academic curriculum examined. The advantages of a vocational curriculum are further discussed by drawing examples from successful case studies. A differentiated curriculum model is suggested, explained and implications for implementation are assessed.

Keywords: Academic curriculum. Vocational education. Employment creation. Different abilities. Secondary school. Zimbabwe

\section{Introduction}

Issues of relevance in education systems are perennial and highly debated. Tied to relevance is the common argument that educational curricula should serve to produce school products that fit in society by serving in different capacities. The Nziramasanga Commission tasked to look into the Zimbabwean education system and provide recommendations for policy planning and curriculum improvement (Nziramasanga, 1999) observed that:

... the current secondary education was academically good but did not cater for the majority of the students, neither did it prepare them for the skills needed in the world of work.

An irrelevant educational system is one that does not imbibe adequate social responsibility. To this end Mahatma Ghandi cited in Sing (2008) notes that true education is one that liberates from different forms of servitude. One form of servitude is the desire to look for a job after receiving an education. In most developing African countries such as Zimbabwe, unemployment levels have reached alarming levels as school graduates continue to be churned out of school systems without basic survival skills.

Solutions to the education system do not lie in making innovations to the curriculum but by transforming the very core of the school system (Whitby, 2010). Whitby (2010) further advocates the need for an education system that caters for the different abilities of learners as opposed to a one size fits all one. In the Zimbabwean education system, curriculum at secondary school level is generally the one size fits all type as all learners are exposed to the mainly academic curriculum, which they have to pass as a route to the so called better life. Murphy (2007) argues for an education system that should prepare students for life. On the view that school system needs change in order to remain relevant, Murphy (2007:1) postulates that:

Systems, just like organisms, must adapt and evolve or become less relevant over time. This is also true for education systems.

The above observation is true for the Zimbabwean secondary educational system whose mainly academic curriculum annual pass rate at Ordinary level stand at an average of less than $18 \%$ for students with a full certificate comprising five subjects with a pass in English Language, the country's official language. With this type of a scenario 
where more than $80 \%$ of students fail a national examination and leave school without any skills for survival, it cannot be business as usual. Even those students who pass Ordinary level end up unemployed as not all proceed to Advanced level or are absorbed by technical colleges. Such an education system requires total revamping to ensure relevance to the needs of students and society in general.

In showing the problems of the Zimbabwean education system Nziramasanga (1999) cited in Mandiudza, Chindedza and Makaye (2013: 125) established that:

... our secondary education was found to be a waste of time for the majority of our students as it handled them as if they all would end up doing Advanced level and university studies.

The above view summarises the challenges of wholly academic curricula in that they address the needs of very few learners who are academically gifted and leaves behind many other learners with talents in other areas. Sadly, even the academically gifted learners seem not do benefit from this type of a curriculum as they remain unemployed even with passes. This is indicative of an educational system that lacks both fitness for purpose and fitness of purpose.

The provision of a type education of education that does not assist the learner in the end is inconsistent with the calls for human rights in education. According to Article 26 of the Universal Declaration of Human Rights and its view on human rights to education:

The aims of education must be directed towards full development of each child's personality and full potential, preparing children to participate in society and to work that is rewarding and remunerative, and to continue learning throughout life.

A situation where large numbers of products from a school system find themselves on the streets without skills that enable them to earn a living, is a typical violation of one's right to education. Access to education should be matched with access to quality education that allows the learner to reach full potential in their areas of ability. A wholly academic curriculum is limiting, discriminatory and purposeless to the majority of the students.

\section{A Differentiated Curriculum}

Curriculum development revolves around epistemological concerns. These are concerns on what is worthwhile knowledge that should be taught in schools. An understanding of the theory of knowledge assists in shaping views about the curriculum. Shay (2013) observes that that there are different types of knowledge and not all forms of knowledge are the same. Therefore, the theory on differentiated knowledge should inform planning of a differentiated curriculum. There is, therefore need for occupationally and professionally oriented curriculum (Shay, 2013). A curriculum can be based on procedural knowledge. Procedural knowledge is information required to accomplish certain tasks. Most vocational skills thrive on procedural knowledge. Conceptual or propositional knowledge, on the other hand, is based on concepts that drive factual pieces of information. Such knowledge is acquired through purposeful and reflective learning and forms the bases of academic curriculum.

Lundvall and Johnson (1994) identify four different types of knowledge that require different types of mastery and these are the know-that, know-why, know-how and the know-who. The know-what and know-why types of knowledge form the basis of an academic curriculum. While the know-what entails knowledge about facts, the know-why refers to scientific knowledge and also involves critical inquiry that results in knowledge production and knowledge reproduction. A vocational curriculum is based on the know-how type of knowledge and these are skills. A learner has to master certain skills related to the vocation so as to become competent in that vocation. In the know-how type of skills the learner may also require important social and language skills that are important in the trade (Rauner et al, 2013).

The researchers take a differentiated curriculum as one that gives learners options to pursue learning in line with their abilities and interests. Such a curriculum does not assume that all learners are the same hence exposed to one curriculum. A learner is assisted to develop to full potential in a chosen area and necessary life skills are developed. Such skills enable products from the school system to serve society meaningfully without looking for formal employment.

\section{Theoretical Framework}

The multiple intelligences theory: This discussion paper is underpinned by the theory of multiple intelligences (MI) theory developed by Gardner in 1983. Gardner defines intelligence as an "ability to solve problems or create products that are valued in at least one culture" (Veenema, Hetland and Chaifen, 1997:1). Davis, Christodoulou, Seder and 
Gardner (2011) argue that individuals draw on these intelligences, individually and corporately to create products and solve problems that are relevant to the societies in which they live.

Gardener (1999) identifies eight intelligences, which include linguistic intelligences that entail the ability to analyse information and create products involving oral and written language such as speeches, books and memos, the logicalmathematical intelligences involve the ability to develop equations and proofs, make calculations, and solve abstract problems. Spatial intelligences involve the ability to recognise and manipulate large scale and fine-grained spatial images, the musical intelligences involve ability to produce, remember and make meaning of different patterns of sound. The bodily-kinesthetic intelligences entail the ability to use one's own body to create products or solve problems the naturalistic intelligences involve the ability to identify and distinguish among different types of plants, animals and weather formations that are found in the natural world. Interpersonal intelligences entail the ability to to recognise and understand other people's moods, desires, motivations and intentions and intrapersonal intelligence involve one's ability to recognise and understand his or her own needs desires, motivations and intentions.

The MI theory regards individuals as possessing a profile of intelligences in which they demonstrate different levels of strengths and weaknesses for each of the eight intelligences. However, individuals may demonstrate low levels of a particular intelligence but all individuals possess the full range of intelligences except in cases involving innate or acquired brain damage (Gardner, 1999).

The theory of multiple intelligences represents a departure from the conceptions of intelligences first formulated in the early twentieth century, measured today by IQ tests. MI theory conceives intelligence as multiple rather than solitary in nature implying the intelligences is a combination of heritable potentials and skills that can be developed in diverse ways through relevant experiences (Gardner, 1983). For example, one individual might be born with a high intellectual potential in the bodily-kinesthetic sphere that allows him or her to master the intricate steps of a ballet performance with relative ease. For another individual achieving a similar expertise in the domain of ballet requires many additional hours of study and practice. Both individuals are capable of becoming strong performers and experts in a domain that draws on their bodily kinesthetic intelligence but the pathway they travel in order to become strong performers may differ in terms of speed and process (Davis, Christodoulou, Seder and Gardner, 2011). With the specified period of the levels of education in the education system, it is important for education planners to consider a curriculum for varying strengths of the different intelligences to be achieved within the specified time.

Curriculum planners and educators should regard all intelligences as equal and important. In his analysis Gardener (1999) indicated that only two intelligences linguistic and logical mathematical intelligences have been valued and tested for in schools in most developing countries and success is determined only on the measured skills in those two intelligences. According to Davis, Christodoulou, Seder and Gardner ( 2011) intelligences in an individual are used simultaneously, usually complementing one another as an individual develops skills or solve problems, for example, a dancer can excel only if he or she has strong musical intelligence to understand the rhythm and variations of the music, interpersonal intelligence to understand how he or she can inspire or emotionally move the audience through his or her emotions and bodily-kinesthetic intelligence to provide physical and co-ordination to execute.

People are born with diverse abilities and interests that have to be nurtured to pursue their vocation and nation building. Zimbabwe recognises that vocationalisation in the education system will ensure the realisation of such inert talents in terms of skills acquisition, thus, the country set to provide technical and vocational education apart from providing general academic education (Coltart, 2012).

\section{Vocational Education}

The mechanisation of processes saw jobs become complex and more specialised, hence a demand for skilled workers. This in turn promoted the growth of an educational curriculum that could provide training and skills for a technically proficient labourer. Vocational Technical Education (VTE) are the educational processes that involve the study of technologies and related sciences and the acquisition of practical skills and knowledge aimed at discovering and developing the individual for employment in various sectors of economic and social life (Boateng, 2012). Wu (2010) points out that vocational and technical education can offer a source of quality living by teaching job skills, family living skills and individual skills.

According to Maclean and Lai (2011) a number of terms have been used to describe elements of this field depending on the specific geographical areas. These are apprenticeship training, vocational education, industrial arts, technical education, Technical/Vocational Education (TVE), Occupational Education (OE), Technical and Vocational Education and Training (TVET) and Career and Technical Education (CTE). For example, in Europe the term VET is common and in USA the current term in use is CTE. In Zimbabwe the term used is Technical and Vocational (Tec-Voc) 
education (Coltart 2012).

Agrawal (2013) notes that vocational education and training (VET) focuses on specific trades and imparts the practical skills which allow individuals to engage in a specific occupational activity. Caillods (1994:241) is of the opinion that,

Vocational education and training are indispensable instruments for improving labor mobility, adaptability and productivity, thus contributing to enhancing firms, competitiveness and redressing labor market imbalances.

Vocational education is very essential in this century in ensuring that the demands for a technically proficient labour force are met, integrating children from the lower socio-economic background and training a loyal and disciplined workforce. VTE is also vital in alleviating mass unemployment, providing specific job skills for employment and selfemployment, preventing mass movement of school leavers from rural to urban areas and re-orienting student attitudes towards the rural society (Agrawal, 2013).

Boateng (2012) declares that vocational technical education has always been planned and implemented with the external environment in mind. The external environment comprises of the local community, the industrial community and the world at large. It is the external environment that serves as the excellent source of employment for product from vocational technical institutions. Vocational education should provide for the needs of the community it serves.

Coltart (2012:3) states that the thrust of the 1999 Presidential Commission of Inquiry into Education and Training in Zimbabwe was "From Education to Employment". Due to the rapid changing socio-economic environment globally there was need for Zimbabwe to focus on reforming education to prepare learners for the challenges of changing times and uncertain future through the provision of diverse skills through the vocationalisation of the educational curriculum.

\section{Case Studies of Countries with Successful Vocational Secondary School Curriculum}

A number of first world countries been successful in implementing the vocational secondary school curriculum. According to Wu (2010) China has made a historic breakthrough development in vocationalising its education. Japan as the world's second largest economic aggregate among the developed countries is also known as one of the most successful countries in vocational education with the development of junior college and specialist schools which are greatly needed. Technical and Further Education (TAFE) is an important pillar of Australia's vocational education system. It is a high quality education and training system which is under the framework of a nation and as an industry driving force with an effective interface between secondary schools and universities.

Germany embarked on vocational training in the $13^{\text {th }}$ century and the training was in the form of "Masters train an apprentice" The Germany states passed the "Vocational Education Law" in August 1969 to ensure success in vocationalisation. United States of America formed a general vocational and technical education system in the 60 s and in 1982 the US economic supremacy introduced the "Vocational Training Cooperation Act" mean to enhance the provision of vocational education in schools and colleges of education (Wu, 2010). Boateng (2012:108) declares that:

Vocational technical education and training in Ghana is currently undergoing restructuring. Many reforms are in place to improve the quality of provision and learning outcomes to make it more accessible and attractive to all and to ensure it is relevant and connected to the world of work.

According to Mandiudza, Chindedza and Makaye (2013:123) vocationalisation in most Secondary Schools in Zimbabwe "is mere window dressing as evidenced by poor to non-implementation of the policy directives in most schools..." Most developing countries are struggling to vocationalise their education curriculum due to a number of factors such as; lack of infrastructure, human resources and equipment.

Botswana in 1998 passed the National Vocational Education and Training policy with the aim to make people employable or self employed and to provide initial training to school leavers. With regards to the fact that in Botswana vocational training is given less emphasis than formal education only 6,7 percent of the school leavers' population have access to vocational training centres (Botswana Federation of Trade Unions, 2007).

In Tanzania the objective of vocational training aimed at the provision of skills for employment and self employment, however, vocational training has not had the highest priority among a range of activities. According to Erik (2001:219) "Better targeting through the formulation of clear objectives and the definition of target groups would facilitate this process..." in implementing vocational training in Tanzania. 


\section{The Academic Nature of the Current Zimbabwean Secondary School Curriculum}

During the colonial period the education system was divided along racial lines. Only half of the black children who proceeded to secondary did academic curriculum. The other half attended vocational school where they were could learn practical skills such as bricklaying, building, dressmaking, carpentry and metalworking. The F2 schools or vocational schools were clearly labelled African. According to Gambanga (2013), the old education system during the colonial era which offered students an opportunity to take up technical subject like building, agriculture, carpentry, food and nutrition and dressmaking at secondary level, so called F2 was much better than the present heavily academic education system. The F2 system was for students not academically inclined, while the other system was for the fast learners of those with academic inclination. Slow learners or less gifted learners were equipped with survival skills early, in that they took up practical subjects and could follow them up to higher levels in industry. At independence Education was declared a basic human right and the government reformed the education system to introduce the academic curriculum to all Zimbabwean candidates. An academic curriculum was prescribed to all.

At independence the government introduced a uniform curriculum for all schools. Zimbabwe's curriculum is centrally and developed by the Curriculum Development Unit (CDU). The centralised curriculum system is meant to ensure curriculum equity uniformity and access in all Zimbabwean secondary schools (Mufanechiya \& Mufanechiya, 2013:332). Subjects currently offered at ' $O$ ' level are Sciences; biology, chemistry, physics, integrated science, and mathematics; Liberal Arts include English literature, geography, history and religious education; Commercial subjects include accounts, commerce, economics, computer sciences; Languages are English, Shona, Ndebele, French , German, Portuguese and Latin ; Practical subjects include woodwork, building, metalwork, agriculture, technical drawing, fashion and fabrics, foods and nutrition, home management, music and Art , physical education. Of all these subjects the candidates are expected to do at least 8 core subjects which are English, ChiShona or IsiNdebele, Mathematics, Science Geography, History, English Literature or Bible knowledge, and a practical subject. At 'O' level students do as many as ten subjects or more but they only do just one or two of the more than ten practical subjects which are available in the curriculum. This scenario indicates a situation where the Zimbabwean curriculum is generally heavily academic and the practical subject's side lined.

While it important to have an academic curriculum it in imperative for any developing country to have a heavy dose of vocational education. Gambanga (2013) observes that some developed countries such as Germany, Japan and China group their students at an as early age as 12 years. The more academically students are allowed to take up subjects that lead them to university where they can study medicine, accountancy, engineering, law, history, etc. On the other hand those who are not academically inclined are allowed to choose one or two of the practical subjects, so that they could after two of more years complete a course that would make them useful members of the economy (Gambanga, 2013). Developing countries such as Zimbabwe need artisan and professionals in such disciplines as mining, farming, motor industry, manufacturing sectors, hotel and tourism. As a result it is critical for the educational system to train and produce plumbers, farmers, miners, printers, builders, carpenters. Education is pivotal for national development and the type of education a country offers will by and large determine the direction the economy takes currently the agriculture and mining contribute more to the Gross Domestic Product (GDP) and the education system should reflect this if is to be relevant (Gambanga, 2013). An academic curriculum with no prospects of work leads to students being frustrated. This is supported by Nkoma et al (2013) who highlight that failure of pupils to comprehend the material taught in the curriculum lead to low performance level and this might cause pupils to skip class or give up altogether.

Due the current economic position of the developing countries like Zimbabwe, there is need to equip student with skills that would enable them to get jobs. At the moment the 'O' Level products do not have skills relevant in the job market, hence they are unemployable.

\section{High Failure Rates at ' $O$ ' and ' $A$ ' Level}

At Ordinary school level in Zimbabwe, concern about lower academic achievement in public examinations has been cited by Nyagura (1991) and Gordon (1995) among others. The situation is particularly worrying because 'O' Level examination is the key in Zimbabwe because it provides potential access to job market opportunities. The proportion of candidates passing 5 or more subjects at ordinary level dropped from 63\% in 1980 to 13\% in 2000 ( Nyagura, 1991; Zimsec, 2002b). Makopa (2011) notes that the performance of the Zimbabwean education system seemed stable from 1995 up to 2000. The situation began to deteriorate from 2000 onwards after the Agrarian Reform programme was introduced. For example, in 2002 and 2003 respectively, 13, 8 and 12, 8\% of learners passed with five or more subjects to gain a full 
Ordinary level certificate (Zimsec, 2002a). The situation has deteriorated to an extent that some schools record a zero percent pass rate. In Manicaland province for example, in 2007, six secondary schools had zero percent pass rates (Annual Report, 2008), while in 2008, eighty-eight secondary schools experienced a zero percent pass rate (Annual Report, 2009). In 2009, seventy-nine secondary schools had zero percent pass rates, (Annual Report, 2010).

According to the Zimsec Report (2004) there were low pass rates at ' $O$ ' level national examinations in Zimbabwe between 1998 and 2001. In 1998 the pass rate was 14,58\%, in 1999 it was 15,69\%, in 2000 it was 13,88\%, in 2001 it was 13,99\%, in 2002 it was $13,80 \%$ and in 2003 pass rate was 12,80\%. In a press statement by Minister of Education, Sports, Art and Culture on performance on the Grade 7, 'O' and 'A' level Zimsec Examinations, on 29 April 2010 , the minister lamented on the poor performance as well the decline of student sitting for $\mathrm{O}$ ' level examinations. The pass rates for the period under review show an upward trend but after a serious decline in 2007, but the figures remained very low. In 2006 national pass rate at O' Level was $20.16 \%$, in 2007 it was 14.32\%, in 2008 it was $14.44 \%$ and in 2009 it was 19.33\% (Minister of Education, Sports, Art and Culture, 2010). The figures clearly give evidence of the poor performance of candidates in their Ordinary Level mostly academic curriculum.

Chakanyuka et al (2009) suggest that the decrease in performance might be explained by the rapid expansion of the education system from as early as 1980 which overstretched the Ministry of Education's resources and capacity, in terms of the human and physical resources. High staff turnover also left schools with untrained teachers especially in the rural areas. Gambanga (2013) points out that one of the flaws of the Zimbabwean education system is that it has a rigid curriculum that assumes that every student will end up at a university. Yet only a fraction of students are capable of reading up to university level. The other problem is the curriculum, in which students are exposed to a heavily academic curriculum. The problem of high failure rate at 'O' Level has persisted to date. In 2012, 171698 candidates were entered for the 'O' Level, 31767 candidates passed with 5 subjects or more and the pass rate was $18.4 \%$ (Newsday, 2012). This means that $81.6 \%$ of candidates who wrote ' $O$ ' Level examinations in 2012 failed the examinations.

At A' level students select a minimum of three main subjects on the basis of their strength of their ' $O$ ' Level passes from the Sciences, Arts and Commercials. This results in better results at ' $A$ ' Level than ' $O$ ' Level. The performance of students at A' Level has been fairly good with the national pass rate being above fifty percent. In 2007 the national pass rate was 75.71\%, in 2008 it was $67.43 \%$ and in 2009 it was 76.88\% (Minister of Education, Sports, Art and Culture, 2010).

\section{Conclusions}

In this presentation the researchers have shown that it is vital for the school curriculum to be planned according to the current needs of the society and produce individuals who will be able to fit into the global labour market. An academic curriculum serves the needs of a few gifted students. The high failure rate in the secondary school terminal examination is indicative of a challenge posed by the current education system. High unemployment rate also shows a sad reality of unemployed and unemployable secondary school products. Offering a differentiated curriculum, with an option to pursue a vocational path seems to be the best way to provide employment opportunities to individuals and also to help enhance productivity. Most developing countries are struggling to implement their set plans on vocationalising the school curriculum. Gardner's Theory of Multiple Intelligences provides a theoretical foundation for recognising the different abilities and talents of learners and the principal claims of the theory are that all individuals possess the full range of intelligences.

\section{Recommendations}

Against conclusions drawn from this discussion paper, the researchers recommend a differentiated curriculum whose model is shown on Figure 1.

A differentiated curriculum model 


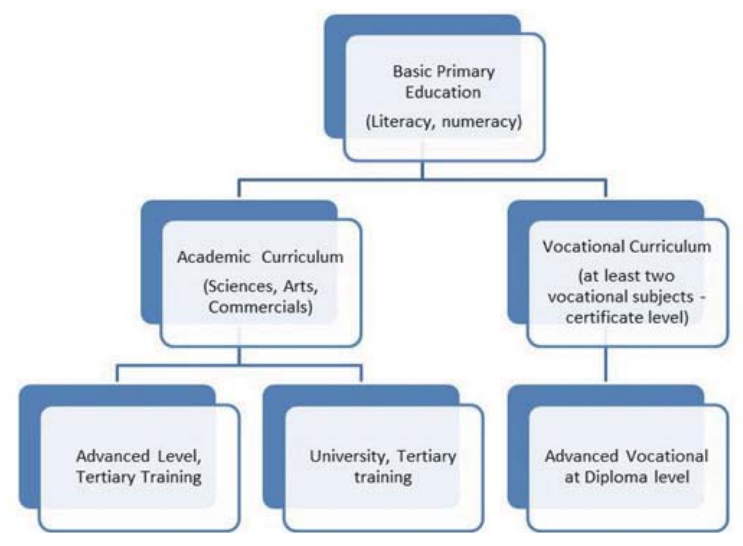

Figure 1: Proposed differentiated curriculum model

\section{How the Model Works}

The current Zimbabwean education system has a basic seven year primary school system and this should remain in place. A solid basic education base is important for future differentiated curriculum pathways. After seven year primary education, learners should have an option of following an academic curriculum that is currently in place or follow a wholly vocational one. The vocational curriculum should allow students to specialise in at least two vocational subjects which they pursue for four years and graduate with a certificate and assessment should establish learners competence in the field of study shown by exhibition of skills in real life contexts. There should be specific schools for different vocations in the same locality such as schools for agriculture, building, cookery, sewing, sport, music, carpentry, business entrepreneurship and many others. Vocational subject specialisations could be combined with each school not offering more than three. Schools should be adequately equipped to offer real-life vocational skills in line with national and international trends. While undergoing studies learners should be involved in the actual wok and this offers training by active engagement in solving societal problems. Students who fail the academic curriculum should be given the opportunity to study for a vocation.

The vocational curriculum pursued by learners for years should teach both the theory and practice of the vocation. Additional courses in literacy and numeracy aligned to the vocation as well as life skills should form part of the curriculum. After successful completion of the four-year vocational curriculum and considerable service to society, graduates should be allowed to advance their skills by joining specific technical colleges for diploma and degree qualifications.

\section{Implications}

The implementation of such a model has serious implications on teacher training. The country would need well trained teachers to implement vocational education not as rudimentary skills but important sought after skills in society. Schools will need to be equipped with the appropriate resources and land provided for agriculture skills with the appropriate mechanisation. Parents will need to be convinced to support children who take the vocational curriculum route by ensuring that sentiments from past experiences of looking down upon vocational subjects are addressed.

\section{References}

Agrawal, T. (2013). Vocational Education and Training Programmes (VET): An Asian Perspective. Asian-Pacific Journal of Cooperative Education. 14(1): 15-26

Annual Report (2008). Grade 7 and Ordinary level Zimsec examination analysis. Manicaland Provincial Education Directorate.

Annual Report (2009). Grade 7 and Ordinary level Zimsec examination analysis. Manicaland Provincial Education Directorate.

Annual Report (2010). Grade 7 and Ordinary level Zimsec examination analysis. Manicaland Provincial Education Directorate.

Boateng, C. (2012). Restructuring Vocational and Technical Education in Ghana: the Role of Leadership Development. International Journal of Humanities and Social Science. 2 (4): 108-114

Botswana Federation of Trade Unions (2007). Policy on education in Botswana. Botswana Federation of Trade Unions (BFTU) 
Gaborone. http:// library,fec,dc/pdf-files/bueros/botswana/04922pdf. Accessed on 18 November 2013.

Caillods, F. (1994). Converging Trends Amidst Diversity in Vocational Training Systems International Labor Review. 133(2): $241-257$

Chakanyuka, S., Chung, F.K., Stevenson, T. (2009). The Rapid assessment of Primary and Secondary schools. Harare: National Advisory Board

Coltart, D. (2012). Education for Employment, Developing Skills for Vocation. Innovation Africa. African Brains. Cape town, South Africa. 5-7 October 2012. http://africanbrains.net/ia/wp-content/uploads/2012 Accessed 31 October 2013

Davis, K., Christodoulou, J., Seider, S., Gardner, H. (2011) Theory of Multiple Intelligences. http://howardgargner01.files.wordpress.com /2012/06/ Accessed 30 October 2013

Erik, L. (2001). Vocational Training for Refugees: A Case Study from Tanzania a accessed on 18 November 2013 at http://www.supportunhr.org/3b8a1b774pdf. Accessed 3 November 2013

Gambanga, J. (2013). Educational Curriculum needs revision. February 12, 2013. http://www.zbc.co.zw/news_catagories/opinion /28319_revise-education_curriculum.html. Accessed 4 November 2013

Gardner, H. (1993). Frames of mind: The Theory of Multiple Intelligences (10 anniversary edition). New York, NY: Basic Books.

Gardner, H. (1999). The Disciplined Mind. What All Students Should Understand. New York: Simon and Schuster.

Lundvall, B., Johnson, B. (1994). The learning economy. Journal of Industrial Studies 1 (2): 23-42.

Maclean, R., Lai, A. (2011). The future of technical and vocational education and training: global challenges and possibilities. International Journal of Training Research. 9(1-2): 2-15

Makopa, Z. (2011). The provision of the basic classroom teaching and learning resources in Zimbabwe Primary schools and their relationship with grade 6 pupils' achievements in the SACMEQ 111 Project. IIEP 2010/2011. Advanced training Programme IN Educational Planning and Research.

Mandiudza, L., Chindedza, W., Makaye, J. (2013). Vocationalisation of secondary schools: implementation reality or fallacy. European Journal of Sustainable Development 2 (1): 123 - 132

Miriam Bar-Yam, Kathleen Rhoades, Linda Booth Sweeney, Jim Kaput, and Yaneer Bar-Yam Changes in the Teaching and Learning Process in a Complex Education System. http://www.necsi.edu/research/management/education/teachandlearn.html. Accessed 11 November 2013

Mufanechiya, T., Mufanechiya, A. (2013). The implementation of A' level English Language and Communication Skills in Zimbabwean Secondary Schools: the Relevance issue. Greener Journal of Educational Research 3(7): 332 - 335

Murphy, M. (2007). The education system is not relevant to the $21^{\text {st }}$ century. Speech given at the $50^{\text {th }}$ anniversary of St Brendans Christian Brothers School. http://arrow. dit.ie/enginedupres. Accessed 7 November 2013

Mwiria, K. (2005). Vocationalisation of secondary education: Kenya case study. In J. Lauglo, R. Maclean (Eds) Vocationalisation of secondary education revisited, International Centre for Technical and Vocational Education and Training \& W Bank Africa Regional Office Human Development Sector, Technical and vocational education and training series vol. 1, Springer, Dordrecht, pp.227-305.

Newsday Zimbabwe (2013). 'O' Level Results Spark Debate, 6 February 2013. http://www.newsday,co,zw/2013/02/05/0-level-out-2/ Accessed on 24 October, 2013.

Nyagura, L.M. (1991). Multilevel Investigation into the Effects of Schools, Classrooms and Student Characteristics on Academic Achievement in Primary Schools in Zimbabwe. Washington DC, World Bank

Nkoma, E, Zirima, H., Chiminhu, J., Nyanga, T. (2013). Tracking Learners Achievement Gap: An Analysis Mathematical Achievement in Manicaland, Zimbabwe. International Journal of Economy, Management and Social Sciences, 2(5): 124-132

Nziramasanga, C.T. et al (1999), Report: Presidential Commission of Inquiry into. Education and Training. Government Printers, Harare

Press Statement by Minister of Education, Sports, Art and Culture on performance in the 2009 Grade 7, 'O' and 'A' level ZIMSEC Examinations; 29 April 2010. http://www.davidcoltat.com/2010/04/press_staten Accessed on 25 October, 2013

Rauner, F., Heinemann, L., Maurer, A., Haasler, B. (2013). Competence Development and Assessment in TVET (COMET). Dordrecht: Springer

Shay, S. (2013). Conceptualizing curriculum differentiation in higher education: a sociology of knowledge point of view. British Journal of Sociology of Education 34 (4): 563 - 582

Sing, M.K. (2008). Gandhi on Education. New Delhi: Rajat Publications

Tomlinson, C.A., Allan, S.D. (2000). Leadership for differentiating schools and classrooms. Alexandria, VA: ASCD.

United Nations Declaration on Human Rights Education, (2011), Article 2 Para 1 and 2 http://www.un.org/document/instrument/doc Accessed on 10 October 25, 2013

Veenema, S., Hetland, L., Chalfen, K., (1997). Multiple Intelligences: The Research Perspective. A brief overview of the Theory, The Project Zero Classroom: Approaches to Thinking and Understanding. Harvard Graduate School of Education and Project Zero. http://ww.learner.org/channel/workshops/socialstudies/pdf/session3/3.Multiplelntelligence/pdf . Accessed 04 November 2013

Wu, G. (2010). The inspiration given by the successful practice of development of higher vocational education in the developed countries. Journal of International Education Studies. 3 (1): 206-209

Whitby, G. (2010). A relevant education for 21st century learners. Getideas.org/thought-leader/relevant-education-todays-learners/ Accessed 7 November 2013

Zimsec (2002a). An analysis of O and A level results for the year 2001. Research and evaluation Division, Harare: Zimsec

Zimsec (2002b). Comparative analysis of O and A level results. Research and evaluation Division, Harare: Zimsec

Zimsec (2004). Comparative analysis of $O$ and A level results. Research and evaluation Division, Harare: Zimsec. 